\title{
Asthma, airway inflammation and epithelial damage in swimmers and cold-air athletes
}

\author{
V. Bougault, J. Turmel, J. St-Laurent, M. Bertrand and L-P. Boulet
}

ABSTRACT: Endurance athletes show an increased prevalence of airway hyperresponsiveness. The aim of the present study was to evaluate the long-term effects of training on airway responsiveness, inflammation and epithelial damage in swimmers and cold-air athletes.

In total, 64 elite athletes (32 swimmers and 32 cold-air athletes), 32 mild asthmatic subjects and 32 healthy controls underwent allergy skin prick testing, methacholine challenge and induced sputum analysis.

Overall, $69 \%$ of swimmers and $28 \%$ of cold-air athletes had airway hyperresponsiveness. Sputum neutrophil count correlated with the number of training hours per week in both swimmers and cold-air athletes. Eosinophil counts were higher in swimmers than in healthy subjects, although they were lower than in asthmatic subjects, and correlated with airway hyperresponsiveness in swimmers only. The eosinophil count in cold-air athletes was similar to that in healthy subjects. Bronchial epithelial cell count was not correlated with airway hyperresponsiveness but was significantly increased in swimmers, compared with healthy and asthmatic controls.

In conclusion, the present authors observed significant airway inflammation only in competitive athletes with airway hyperresponsiveness. However, the majority of elite athletes showed evidence of bronchial epithelial damage that could possibly contribute to the development of airway hyperresponsiveness.

KEYWORDS: Airway hyperresponsiveness, airway inflammation, asthma, athletes, epithelial damage

E xercise-induced asthma is frequently reported by endurance athletes [1]. During exercise, conditioning of large volumes of inspired air leads to drying and cooling of the conducting airways, with the resulting airway fluid hyperosmolarity being considered the main mechanism involved in exercise-induced bronchoconstriction (EIB) [2] EIB may also be enhanced by the constituents and characteristics of inhaled air [3]. Since swimmers and cold-air athletes spend many hours per week training in cold, dry air or a chlorinated environment, they are particularly affected by respiratory symptoms and airway hyperresponsiveness (AHR) [3].

A mixed type of airway inflammation, mostly made up of neutrophils and eosinophils, has been observed in swimmers and cross-country skiers [4-7]. However, whether such airway inflammation is associated with AHR in athletes has to be further documented [5-7]. Furthermore, airway damage, as evidenced by increased bronchial epithelial shedding, may play a role in the development of AHR in asthma [8].
Such epithelial shedding may be involved in the largely result from specific environmental exposures. Epithelial damage may occur during intense exercise $[9,10]$. Epithelial damage has also been observed after long-term training in cold air and after as little as $2 \mathrm{~h}$ of swimming activities in a chlorinated swimming pool [11]. It has recently been hypothesised that the inspired air conditioning process required during athletes' training may render bronchial epithelial cells more susceptible to dehydration injuries following high levels of ventilation, particularly in cold air [2]. The epithelial cells could then release inflammatory mediators and be, in part, responsible for the airway neutrophilia observed in athletes [2]. The repair process of epithelial cells seems to involve plasma exudation, thus exposing the airways to plasma-derived products. When repeated many times per week and several times per day for a prolonged time-period, in the case of elite swimmers and cold-air athletes, the injury-repair process may affect the contractile properties of the airway smooth muscle and lead to AHR. Whether epithelial damage persists beyond training periods, development of asthma in athletes, and may
AFFILIATIONS

*Unité de Recherche en

Pneumologie, Centre de Recherche de l'Institut Universitaire de Cardiologie et de Pneumologie de Québec

Quebec, QC, Canada

CORRESPONDENCE

L-P. Boulet

Institut Universitaire de Cardiologie et de Pneumologie de Québec

2725 chemin Sainte-Foy

Québec

QC

G1V 4G5

Canada

Fax: 14186564762

E-mail: Ipboulet@med.ulaval.ca

Received:

July 312008

Accepted after revision:

November 282008

SUPPORT STATEMENT

V. Bougault was supported in part by a grant from the Groupe de recherche en santé respiratoire of Université Laval,

Québec, QC, Canada.

STATEMENT OF INTEREST

A statement of interest for L-P. Boulet can be found at

www.erj.ersjournals.com/misc/

statements.dtl 
however, remains to be documented, as a persistent altered or impaired repair process of the airway epithelium may possibly contribute to AHR.

The present authors hypothesised that chlorine or cold-air exposure could produce different persistent inflammatory and epithelial damage patterns in high-level athletes. In this regard, "swimmers' asthma" and "skiers' asthma" may be different from the classical form of asthma, with respect to airway inflammatory features. The aim of the present study was therefore to compare pulmonary function, airway responsiveness and inflammation in swimmers and cold-air athletes.

\section{METHODS}

\section{Subjects}

A total of 100 high-level competitive athletes aged $>14$ yrs were recruited. Of these, 19 (37\%) cold-air athletes and $17(35 \%)$ swimmers were excluded from the study owing to their inability to produce sputum. The present authors thus analysed data from 64 competitive athletes from provincial to international level, who were able to produce sputum after induction, comprising 32 swimmers and 32 cold-air athletes (11 speed skaters training at an outdoor ice-rink, 16 cross-country skiers and five biathletes). They were compared with: 32 healthy nonathlete subjects without respiratory disease and with normal airway responsiveness, as shown by the fact that the concentration of inhaled methacholine causing a $20 \%$ fall in forced expiratory volume in one second (PC20) was $\geqslant 16 \mathrm{mg} \cdot \mathrm{mL}^{-1}$; and 32 nonathlete subjects with symptomatic mild asthma and a PC20 $<16 \mathrm{mg} \cdot \mathrm{mL}^{-1}$. The control groups were matched for age and atopy with the swimmers and cold-air athletes. All subjects were nonsmokers, nonobese and free of any disease that might have interfered with the study. All subjects gave their written informed consent and the study protocol was approved by the institutional ethics committee of the Hôpital Laval (Quebec, QC, Canada).

\section{Study design}

Each examination was performed when the athletes had not trained for $\geqslant 12 \mathrm{~h}$. Most tests were conducted in the autumn. Short-acting inhaled $\beta_{2}$-agonists, leukotriene receptor antagonists and inhaled corticosteroids were stopped $\geqslant 12,24$, and $48 \mathrm{~h}$ before the examinations, respectively. A physical examination and allergy skin prick tests were performed. A locally developed standardised questionnaire was administered to the athletes; it documented their past or present history of asthma and exercise-induced asthma-like symptoms (EIS). A methacholine challenge and sputum induction were also carried out. Asthma was defined as the presence of asthma symptoms with proven airway obstruction [12].

Allergy skin prick tests, baseline expiratory flows and methacholine challenge were carried out as described previously [13]. A subject was classified as atopic if at least one allergen caused a weal of $\geqslant 3 \mathrm{~mm}$ in diameter, in the presence of a negative saline control and positive histamine control. A subject was considered to have AHR if their methacholine PC20 was $<16 \mathrm{mg} \cdot \mathrm{mL}^{-1}$.

Sputum was induced and processed as described by PIZZICHINI et al. [14]. Briefly, concentrations of 3\%, $4 \%$ and $5 \%$ hypertonic saline were inhaled for $7 \mathrm{~min}$ each via a Medix electronic nebuliser (Medix, Catthorpe, UK). After each inhalation, subjects were asked to blow their nose and rinse their mouth with water to minimise post-nasal drip and squamous epithelial cell contamination, respectively, and to expectorate into a sterile container. Sputum was processed within $2 \mathrm{~h}$ after induction. Mucus was selected from saliva and weighed, and four equal volumes of $0.1 \%$ dithiothreitol (Sputolysin; Calbiochem-Novabiochem, San Diego, CA, USA) were added. Samples were rocked for $15 \mathrm{~min}$. The reaction was stopped by adding four equal volumes of Dulbecco's PBS $1 \times, \mathrm{pH} 7.1$ (Invitrogen, Burlington, ON, Canada). Following filtration, total cell count and viability were determined using the trypan blue exclusion method. Cell suspension was centrifuged at $800 \times g$ for $4 \mathrm{~min}$. Cells were resuspended to a final concentration of $1 \times 10^{6}$ cells $\cdot \mathrm{mL}^{-1}$. Cells were mixed well before being transferred into cytofunnels for cytospin preparation. Slides were prepared with $\sim 0.07 \times 10^{6}$ cells for differential count. The cell count was made by two investigators blinded to the clinical characteristics of the subjects. The sputum sample was considered adequate if it was contaminated by $<20 \%$ squamous epithelial cells from saliva. The reproducibility of the technique has been described previously [15].

\section{Analysis}

Data were expressed as mean $\pm \mathrm{SD}$, except for airway inflammatory cells, which were expressed as median (range). ANOVA was used to compare the four groups. Subjects with a PC20 > $128 \mathrm{mg} \cdot \mathrm{mL}^{-1}$ were assigned a PC20 of $128 \mathrm{mg} \cdot \mathrm{mL}^{-1}$ for the statistical analyses. Statistical results from these parameters were expressed using log-transformed values. The Tukey's multiple comparisons technique was applied post hoc to the ANOVA. Univariate normality assumptions were verified with the Shapiro-Wilk test, and Brown-Forsythe's modification of the Levene's test was used to verify the homogeneity of variances. Stepwise regression analyses were performed to determine the relationship between inflammatory cells and the variables (sex, allergies, physician-diagnosed asthma, AHR, training level, hours and years, swimmers or cold-air athletes and EIS). A p-value of $\leqslant 0.05$ was considered statistically significant.

\section{RESULTS}

\section{Characteristics of the subjects}

Subjects' characteristics are presented in table 1. Athletes were mostly national- and international-level Canadian athletes (20 swimmers and 27 cold-air athletes) while some were at provincial level (12 swimmers and five cold-air athletes). Three $(9 \%)$ swimmers and two $(6 \%)$ cold-air athletes had a diagnosis of asthma during childhood, all before the age of 12 yrs and before initiating their respective sports' training programmes.

The prevalence of AHR for each group is reported in figure 1. In total, $22(69 \%)$ swimmers and nine (28\%) cold-air athletes were hyperresponsive to methacholine using the PC20 $<16 \mathrm{mg} \cdot \mathrm{mL}^{-1}$ threshold. No significant correlation was observed between age, years of training and AHR in athletes.

Exercise-induced respiratory symptoms were reported by 15 (47\%) swimmers, 14 with AHR and one without AHR, and by $20(63 \%)$ cold-air athletes, five with AHR and 15 without AHR (fig. 2). Cold-air athletes were more likely to report cough than swimmers $(p<0.05)$. In swimmers, EIS were negatively correlated with PC20 $(\mathrm{r}=-0.48, \mathrm{p}<0.05)$. However, this was 


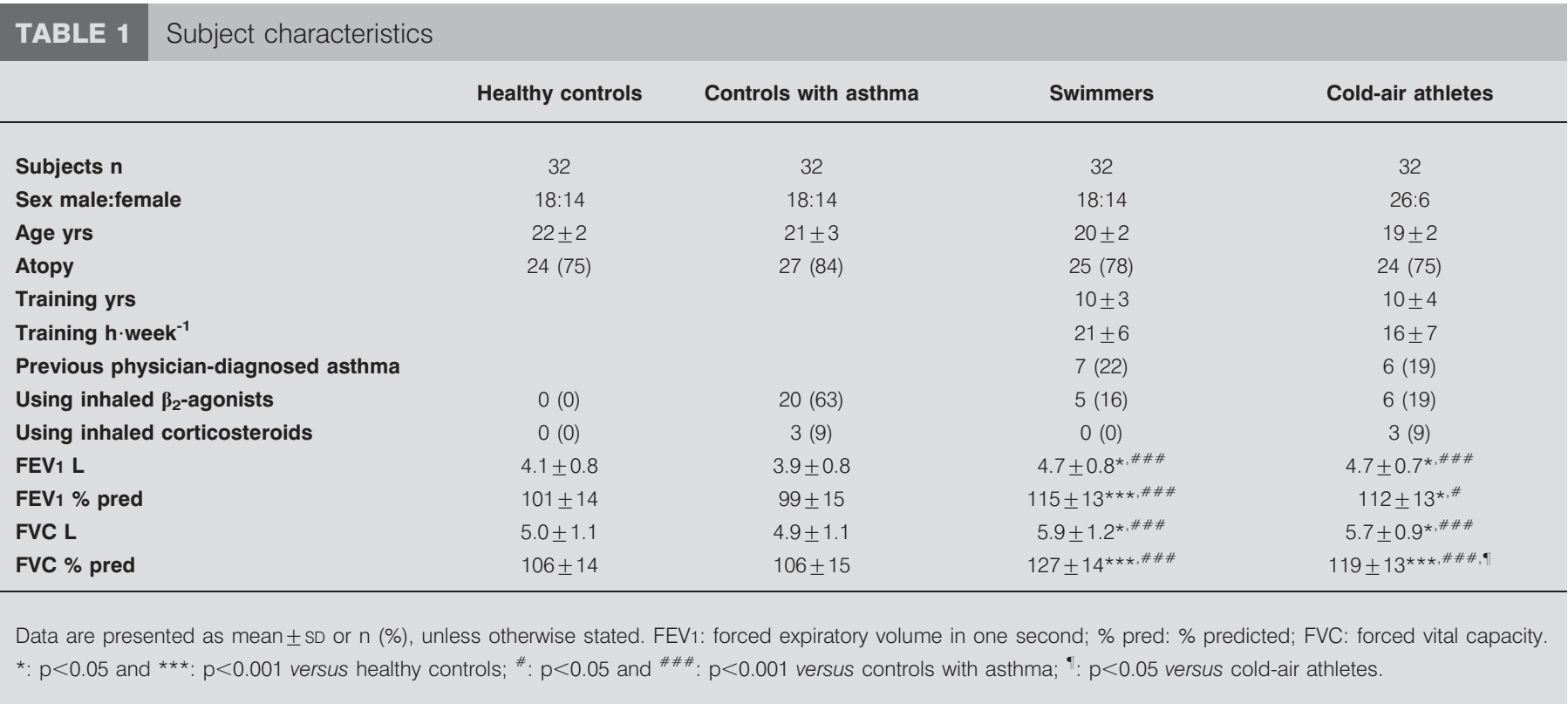

not the case in cold-air athletes $(\mathrm{r}=-0.04, \mathrm{p}>0.05)$. Sputum production was a respiratory symptom rarely reported by the athletes after training.

\section{Inflammatory cell counts}

Total cell counts and viability were similar in the four groups (table 2). No significant differences were noted in the total number of each type of inflammatory cell per gram of sputum, except for macrophages, which were more numerous in the cold-air athletes group than in swimmers or in controls with asthma $(\mathrm{p}<0.05)$. Compared with the 49 atopic athletes, the 15 without atopy showed no significant difference in inflammatory cell counts.

Asthmatic controls had a higher percentage of eosinophils than healthy controls $(p<0.001)$, swimmers $(p<0.005)$ or cold-air athletes $(p<0.001)$. Swimmers had a higher percentage of

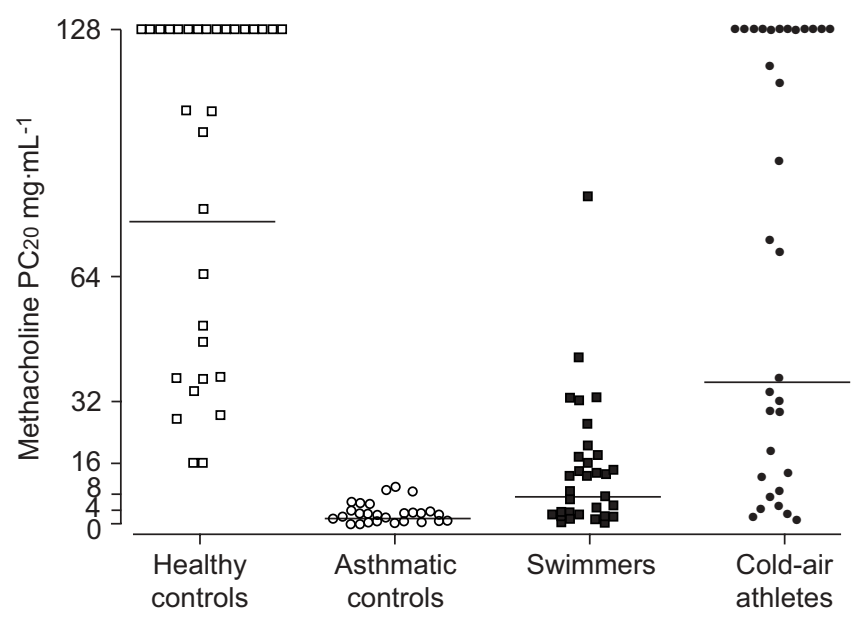

FIGURE 1. Airway responsiveness of the four groups studied. Solid horizontal lines represent geometric means for each group. Methacholine PC20: concentration of inhaled methacholine causing a $20 \%$ fall in forced expiratory volume in one second. All groups $n=32$ eosinophils than healthy controls $(\mathrm{p}<0.01)$, while cold-air athletes had a similar eosinophil count compared with healthy controls. The whole group of athletes had lower percentages of eosinophils than controls with asthma $(\mathrm{p}<0.005)$. Sputum eosinophil count was correlated with AHR in swimmers only $(r=0.64, p<0.0001)$

Neutrophil count was similar in athletes with or without AHR (table 3). However, both swimmers and cold-air athletes with AHR had a higher percentage of sputum eosinophils than athletes without AHR $(\mathrm{p}<0.05)$. Athletes with or without AHR had similar neutrophil counts compared with healthy controls (tables 2 and 3).

Cold-air athletes without EIS had a higher percentage of neutrophils than cold-air athletes with EIS $(p<0.01)$ and swimmers without EIS ( $p<0.01$; table 4$)$. Swimmers with EIS had a higher percentage of eosinophils than swimmers without EIS and cold-air athletes with EIS $(p<0.001)$. Furthermore, percentages of sputum neutrophils were correlated with the number of training hours per week in the two groups of athletes $(p<0.005$; fig. 3$)$.

\section{Epithelial cells}

The percentage of bronchial epithelial cells was increased in swimmers compared with healthy controls and controls with asthma $(\mathrm{p}<0.05$; table 2 ; fig. 4$)$. In cold-air athletes, there was a slight increase in epithelial cells in sputum compared with healthy controls, but this was not statistically significant $(p=0.13)$. The percentage of bronchial epithelial cells was high in swimmers with or without AHR or EIS compared with controls $(p<0.05)$. No correlation was observed between epithelial cell counts and eosinophil or neutrophil cell counts. Epithelial cell counts were not correlated with AHR.

\section{DISCUSSION}

The present study found minimal or no airway inflammation in high-level swimmers and cold-air athletes who had not exercised in the previous $12 \mathrm{~h}$, except for those with AHR, who had a slight but significant increase in airway eosinophil count, 

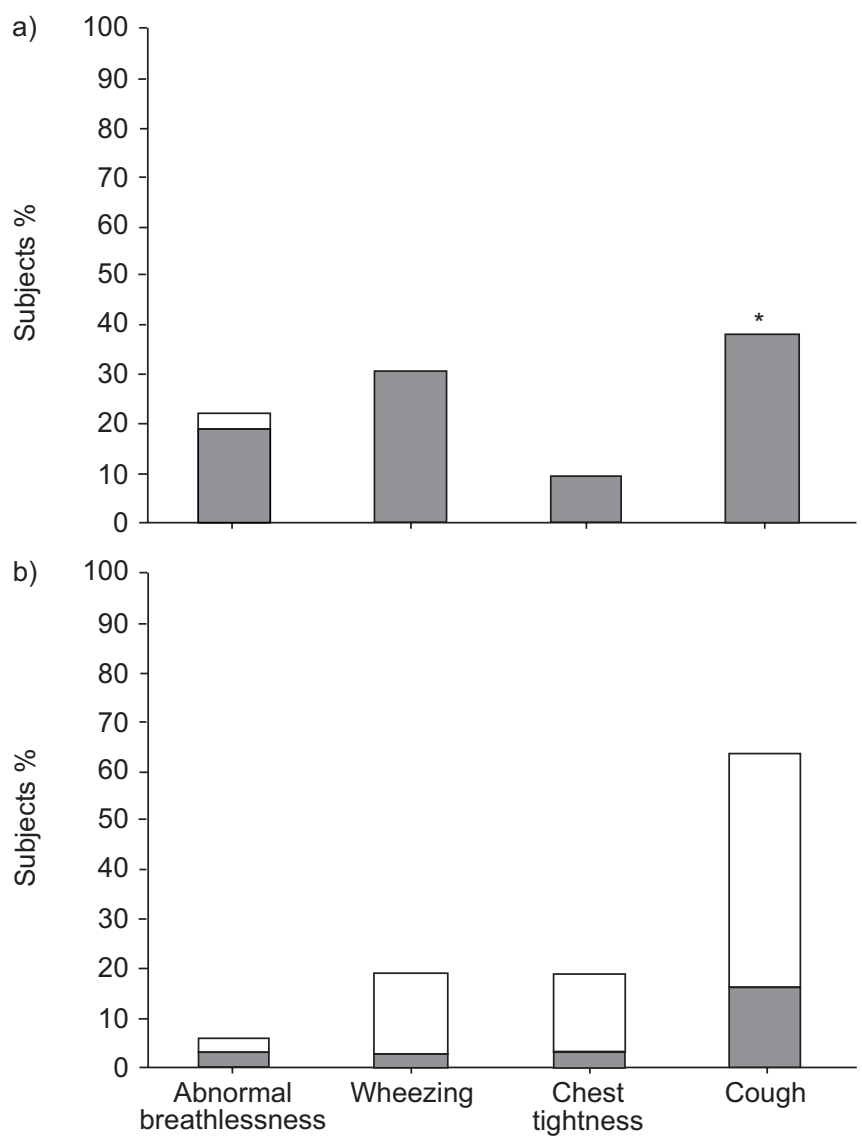

FIGURE 2. Exercise-induced asthma-like symptoms reported by a) swimmers and b) cold-air athletes, with ( $\square$ ) or without $(\square)$ airway hyperresponsiveness, defined as concentration of inhaled methacholine causing a $20 \%$ fall in forced expiratory volume in one second $<16 \mathrm{mg} \cdot \mathrm{mL}^{-1}$. *: $\mathrm{p}<0.05$ between cold-air athletes and swimmers. Both groups $\mathrm{n}=32$.

particularly in the swimmers group. A key original finding of the current study, however, was the high degree of persistent epithelial cell shedding in induced sputum observed in athletes. This was particularly marked in swimmers. Such an increase in sputum bronchial epithelial cell count was not associated with airway inflammation but suggests significant underlying airway damage.

\begin{tabular}{|c|c|c|c|c|}
\hline \multirow[t]{3}{*}{ TABLE 3} & \multicolumn{4}{|c|}{$\begin{array}{l}\text { Sputum neutrophil and eosinophil percentages } \\
\text { in swimmers and cold-air athletes according to } \\
\text { airway responsiveness }\end{array}$} \\
\hline & \multicolumn{2}{|c|}{ Swimmers } & \multicolumn{2}{|c|}{ Cold-air athletes } \\
\hline & With AHR & Without AHR & With AHR & Without AHR \\
\hline Subjects n & 22 & 10 & 9 & 23 \\
\hline Neutrophils \% & $\begin{array}{c}37.5(34.9- \\
40.1)\end{array}$ & $\begin{array}{c}36.5(31.2- \\
41.7)\end{array}$ & $\begin{array}{c}42.7(36.8- \\
48.6)\end{array}$ & $\begin{array}{c}36.5(33.1- \\
39.2)\end{array}$ \\
\hline Eosinophils \% & $\begin{array}{c}1.8(1.5- \\
2.1)^{\star}\end{array}$ & $\begin{array}{c}0.3(0.2- \\
0.3)\end{array}$ & $\begin{array}{c}1.4(0.8- \\
2.0)^{*}\end{array}$ & $\begin{array}{c}0.3(0.2- \\
0.3)\end{array}$ \\
\hline
\end{tabular}

In the present study, neutrophil count in the athletes was in the range observed in healthy subjects. This has also been reported by BELDA et al. [16], showing that neutrophils may come back within the normal range in the $12 \mathrm{~h}$ following the last training session, with eosinophils remaining slightly elevated in athletes with AHR. The possibility that airway remodelling in athletes following repeated intense exercise could be protective and constitute a mechanism limiting the inflammatory process cannot be excluded [17]. BELDA et al. [5] attributed the neutrophilic inflammation seen in swimmers to the effects of chlorinated pool exposure rather than to the number of training hours. In the present study, however, airway neutrophil count was strongly correlated with the number of training hours, whatever the specific environment. These observations are in keeping with the report of BONSIGNORE et al. [18], showing a correlation between the presence of neutrophilic inflammation and the number of training hours, and between eosinophilic or lymphocytic inflammation and environmental exposure during training.

Loss of epithelial integrity can be observed in asthmatic airways [19]. However, the present study found no increase in bronchial epithelial cell count in induced sputum in the controls with asthma, probably due to their mild disease, while significant evidence of epithelial damage was found in

TABLE 2 Sputum cell counts in controls, asthmatics, swimmers and cold-air athletes

\begin{tabular}{lcccc} 
& Healthy controls & Controls with asthma & Swimmers & Cold-air athletes \\
\hline Subjects $\mathbf{n}$ & 32 & 32 & 32 & 32 \\
Total cell count cells $\mathbf{g}^{-1}$ & $4.9 \pm 5.0$ & $3.5 \pm 5.1$ & $4.2 \pm 3.3$ & $5.4 \pm 4.6$ \\
Cell viability \% & $67 \pm 14$ & $71 \pm 17$ & $68 \pm 19$ & $69 \pm 27$ \\
Neutrophils \% & $24.4(2.0-95.3)$ & $21.6(1.0-76.3)$ & $34.8(7.0-68.8)$ & $21.6(4.3-80.5)^{\#}$ \\
Eosinophils \% & $0.1(0-3.5)$ & $2.6(0-36.1)^{\text {\% }}$ & $0.8(0-6.8)^{* . *}$ & $0.1(0-7.8)^{\# \# \#}$ \\
Macrophages \% & $71.6(2.0-89.5)$ & $68.3(5.5-88.0)$ & $52.4(20.0-92.0)$ & $59.0(7.3-91.5)$ \\
Lymphocytes \% & $1.5(0-4.8)$ & $1.4(0-8.8)$ & $1.3(0-6.8)$ & $1.0(0-3.3)$ \\
Bronchial epithelial cells \% & $0.8(0-11.8)$ & $1.1(0-11.9)$ & $2.9(0.5-20.4)^{* \text { *.\# }}$ & $2.5(0.5-11.8)$ \\
\hline
\end{tabular}

Data are presented as mean $\pm S D$ or median (range), unless otherwise stated. ${ }^{*}: p<0.05$ versus healthy controls; ${ }^{*}: p<0.05$ and ${ }^{\# \# \#: ~} p<0.001$ versus controls with asthma; ${ }^{\cdots}: p<0.001$ versus healthy controls. 


\begin{tabular}{|c|c|c|c|c|}
\hline \multirow[t]{2}{*}{ Sputum indices } & \multicolumn{2}{|c|}{ Swimmers } & \multicolumn{2}{|c|}{ Cold-air athletes } \\
\hline & With EIS & Without EIS & With EIS & Without EIS \\
\hline Subjects $n$ & 17 & 15 & 20 & 12 \\
\hline
\end{tabular}

athletes. Such damage, more marked in swimmers, may be due to mechanical stress of breathing at large volumes during training and/or repeated intense hyperventilation and resultant dehydration of the mucosa and shear stress on the airway wall $[9,10,20]$. The release of fibrogenic factors has been observed when epithelial cells are submitted to repeated external pressure [20]. The epithelial shedding may also be a result of specific environmental exposures, particularly in chlorinated swimming pools. Additionally, cold, dry air may be an important stimulus for epithelial cell shedding in the human nose at rest [21] and in horses' airways during exercise [22]. Repeated cold-air inhalation may also be responsible for AHR in cold-air athletes, through repeated exposure to plasma-derived products, resulting from the repair process induced by airway dehydration [2]. The present authors believe that exposure to chlorine derivatives can enhance exercise-induced bronchial epithelial cell shedding, explaining the difference in epithelial cell counts observed between coldair athletes and swimmers. Recent studies have shown that occasional exposure to low levels of chlorine in recreational swimmers or children attending swimming lessons causes transient lung epithelial damage [23]. Moreover, during acute accidental chlorine exposure, severe epithelium destruction and desquamation usually occurs [24].

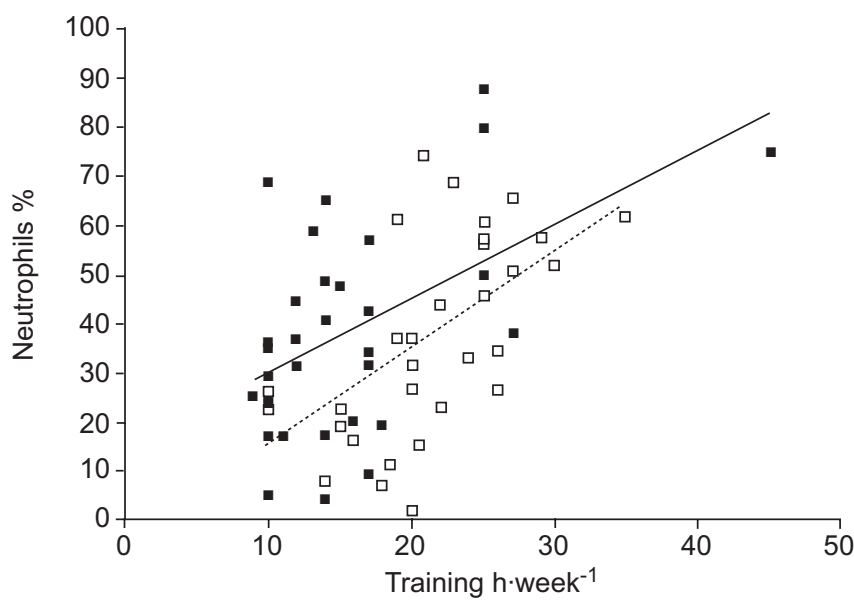

FIGURE 3. Relationship between hours of training per week and percentage of neutrophils in the airways of swimmers $(\square)$ and cold-air athletes ( $\square)$. swimmers $(r=0.58, p<0.0005) ;-\cdots$ - cold-air athletes $(r=0.52, p<0.005)$.
Epithelial shedding may reflect alterations in the airway epithelium and this epithelial damage may possibly play a role in the development of AHR. It has previously been shown that bronchial epithelium modulates the responsiveness of airway smooth muscle and that the dysfunction or absence of the epithelium could contribute to abnormal responses of the bronchial tone [25]. Airway epithelium is the first line of defence protecting sensory nerves and smooth muscle from stimulation by inhaled irritants. When the epithelial layer is damaged, the sensory nerves are more directly exposed, releasing neuropeptides that may induce a bronchoconstriction [26]. Disruption of the epithelial layer may be responsible for increased permeability of the diffusion barrier, which may facilitate the penetration of inhaled irritants and allergens into the underlying smooth muscle or blood [27]. CARBONELLE et al. [11] and BERNARD et al. [23] reported that cumulative school pool attendance was positively correlated with the serum concentration of blood pneumoproteins, indicating increased alveolo-capillar permeability and thus epithelial damage. Epithelial damage may also contribute to AHR through the loss of synthesis of epithelium-derived relaxing factors, such as prostaglandin E2 and nitrous oxide, which normally prevent the airways from constricting [25]. Another mechanism

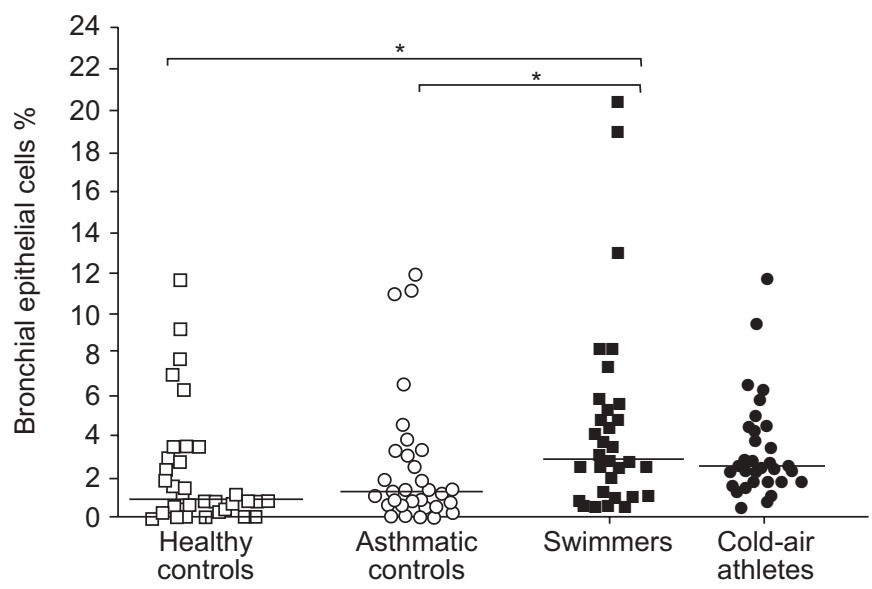

FIGURE 4. Bronchial epithelial cells in induced sputum for the four groups Solid horizontal lines represent medians for each group. Medians (ranges) for each group are: $0.8 \%(0-11.8 \%)$ in healthy controls; $1.1 \%(0-11.9 \%)$ in controls with asthma, 2.9\% (0.5-20.4\%) in swimmers; and 2.5\% (0.5-11.8\%) in cold-air athletes. *: $p<0.05$ versus healthy or asthmatic controls. All groups $n=32$. 
possibly contributing as much as or even more than underlying inflammation to AHR is the remodelling process. Airway remodelling is characterised by changes in the quantity, composition and organisation of the cellular and molecular components of the airway wall, alterations considered secondary to chronic injury and repair of the airway epithelialmesenchymal trophic unit [28]. Disruption of this trophic state, for example following airway injury, may lead to airway remodelling $[20,28]$. Epithelial cell count in induced sputum, as measured in the present study, reflects epithelial shedding and thus an injury to bronchial epithelium, which may be responsible for the activation of a process leading to airway remodelling. In support of this, significant airway remodelling has been documented in cross-country skiers, even without asthma, and with variable degrees of airway inflammation [6, 7]. It is therefore possible that swimmers and cold-air athletes develop AHR and asthma through a mechanism somewhat different from the classical forms of asthma.

The current observations may explain the reduced effectiveness of asthma drugs observed in athletes [29, 30]. Exerciseinduced cough, the predominant symptom in cold-air athletes, is probably not due primarily to asthma or to airway inflammation, but rather to a neurogenic reflex-mediated, lower-airway response to cooling of the skin or upper airways, or to the dryness of cold air [31]. The mechanisms of skiers' cough also remain to be investigated, as do the effects of EIS and AHR on athletic performance and quality of life.

Finally, the subjects excluded from the present analysis because of their inability to produce sputum were not different from the athletes included in the present study in regard to airway responsiveness. A majority of subjects were atopic, and this could have influenced baseline airway inflammation. However, control subjects were matched for atopy with athletes and the study was mostly performed in the autumn, when the pollen season was over. The lack of correlation between EIS and inflammatory cell counts of induced sputum in athletes could be explained by the fact that measurements were obtained at rest and not immediately after exercise. However, the increased bronchial epithelial cell counts at rest may indicate a persistent epithelial shedding after exercise that may have been responsible for EIS or may be involved in airway remodelling. Because the first aim of the current study was to observe the persistence of inflammation and epithelial shedding in the induced sputum of athletes, and to compare this with the classical form of asthma, no analysis of biochemical markers in sputum was performed.

Although this needs to be studied, Helenius et al. [4] have shown a reversibility of airway responsiveness in swimmers who have stopped their sporting career, and that may be associated with a restorative process of the epithelium after repeated injuries. The current study suggests an epithelial shedding $\geqslant 12 \mathrm{~h}$ after the last training session. The time-course of changes in epithelial damage, airway cell composition and AHR after a rest period remains to be documented in athletes in order to better understand the mechanisms of AHR.

In conclusion, analysis of induced sputum in elite athletes during a period without recent training uncovered slight persistent airway inflammation, as indicated by an increase in eosinophil counts, but only in athletes with airway hyperresponsiveness. Airway neutrophil counts were correlated to the current weekly duration of training. Exercise-induced symptoms, especially cough, were not associated with either airway hyperresponsiveness or airway inflammation in cold-air athletes. Epithelial desquamation was documented in athletes, particularly in swimmers, while it was minimal or absent in healthy subjects or controls with asthma. These results suggest that bronchial epithelial damage, following repeated highventilation episodes in cold air or in chlorinated pools, may contribute to airway remodelling that, in turn, may cause airway hyperresponsiveness in susceptible athletes.

\section{REFERENCES}

1 Haahtela T, Larsson K, Bonini S. Epidemiology of asthma, allergy and bronchial hyperresponsiveness in sports. In: Carlsen K-H, Delgado L, Del Giacco S, eds. Diagnosis, Prevention and Treatment of Exercise-Related Asthma, Respiratory and Allergic Disorders in Sports. Eur Respir Mon 2005; 33: 1-4.

2 Anderson SD, Kippelen P. Airway injury as a mechanism for exercise-induced bronchoconstriction in elite athletes. $J$ Allergy Clin Immunol 2008; 122: 225-235.

3 Bjermer L, Anderson SD. Bronchial hyperresponsiveness in athletes: mechanisms for development. In: Carlsen K-H, Delgado L, Del Giacco S, eds. Diagnosis, Prevention and Treatment of Exercise-Related Asthma, Respiratory and Allergic disorders in Sports. Eur Respir Mon 2005; 33: 35-47.

4 Helenius I, Rytila P, Sarna S, et al. Effect of continuing or finishing high-level sports on airway inflammation, bronchial hyperresponsiveness, and asthma: a 5-year prospective follow-up study of 42 highly trained swimmers. J Allergy Clin Immunol 2002; 109: 962-968.

5 Belda J, Ricart S, Casan P, et al. Airway inflammation in the elite athlete and type of sport. Br J Sports Med 2007; 42: 244-248.

6 Karjalainen EM, Laitinen A, Sue-Chu M, Altraja A, Bjermer L, Laitinen LA. Evidence of airway inflammation and remodeling in ski athletes with and without bronchial hyperresponsiveness to methacholine. Am J Respir Crit Care Med 2000; 161: 2086-2091.

7 Sue-Chu M, Larsson L, Moen T, Rennard SI, Bjermer L. Bronchoscopy and bronchoalveolar lavage findings in cross-country skiers with and without "ski asthma". Eur Respir J 1999; 13: 626-632.

8 Montefort S, Roche WR, Holgate ST. Bronchial epithelial shedding in asthmatics and non-asthmatics. Respir Med 1993; 87: Suppl. B, 9-11.

9 Chimenti L, Morici G, Paterno A, et al. Endurance training damages small airway epithelium in mice. Am J Respir Crit Care Med 2007; 175: 442-449.

10 Morici G, Bonsignore MR, Zangla D, et al. Airway cell composition at rest and after an all-out test in competitive rowers. Med Sci Sports Exerc 2004; 36: 1723-1729.

11 Carbonnelle S, Francaux M, Doyle I, et al. Changes in serum pneumoproteins caused by short-term exposures to nitrogen trichloride in indoor chlorinated swimming pools. Biomarkers 2002; 7: 464-478. 
12 Bateman ED, Hurd SS, Barnes PJ, et al. Global strategy for asthma management and prevention: GINA executive summary. Eur Respir J 2008; 31: 143-178.

13 Langdeau JB, Turcotte H, Bowie DM, Jobin J, Desgagne P, Boulet LP. Airway hyperresponsiveness in elite athletes. Am J Respir Crit Care Med 2000; 161: 1479-1484.

14 Pizzichini MM, Popov TA, Efthimiadis A, et al. Spontaneous and induced sputum to measure indices of airway inflammation in asthma. Am J Respir Crit Care Med 1996; 154: 866-869.

15 Spanevello A, Migliori GB, Sharara A, et al. Induced sputum to assess airway inflammation: a study of reproducibility. Clin Exp Allergy 1997; 27: 1138-1144.

16 Belda J, Leigh R, Parameswaran K, O’Byrne PM, Sears MR, Hargreave FE. Induced sputum cell counts in healthy adults. Am J Respir Crit Care Med 2000; 161: 475-478.

17 Pastva A, Estell K, Schoeb TR, Atkinson TP, Schwiebert LM. Aerobic exercise attenuates airway inflammatory responses in a mouse model of atopic asthma. $J$ Immunol 2004; 172: 4520-4526.

18 Bonsignore MR, Morici G, Vignola AM, et al. Increased airway inflammatory cells in endurance athletes: what do they mean? Clin Exp Allergy 2003; 33: 14-21.

19 Wang Y, Bai C, Li K, Adler KB, Wang X. Role of airway epithelial cells in development of asthma and allergic rhinitis. Respir Med 2008; 102: 949-955.

20 Tschumperlin DJ, Drazen JM. Chronic effects of mechanical force on airways. Annu Rev Physiol 2006; 68: 563-583.

21 Cruz AA, Naclerio RM, Proud D, Togias A. Epithelial shedding is associated with nasal reactions to cold, dry air. J Allergy Clin Immunol 2006; 117: 1351-1358.
22 Davis MS, Lockard AJ, Marlin DJ, Freed AN. Airway cooling and mucosal injury during cold weather exercise. Equine Vet J Suppl 2002; 34: 413-416.

23 Bernard A, Carbonnelle S, Michel O, et al. Lung hyperpermeability and asthma prevalence in schoolchildren: unexpected associations with the attendance at indoor chlorinated swimming pools. Occup Environ Med 2003; 60: 385-394.

24 Lemière $C$, Malo JL, Boutet $M$. Reactive airways dysfunction syndrome due to chlorine: sequential bronchial biopsies and functional assessment. Eur Respir J 1997; 10: 241-244.

25 Vanhoutte PM. Epithelium-derived relaxing factor(s) and bronchial reactivity. J Allergy Clin Immunol 1989; 83: 855-861.

26 Goldie RG, Fernandes LB, Farmer SG, Hay DW. Airway epithelium-derived inhibitory factor. Trends Pharmacol Sci 1990; 11: 67-70.

27 Bernard A. Chlorination products: emerging links with allergic diseases. Curr Med Chem 2007; 14: 1771-1782.

28 Bai TR, Knight DA. Structural changes in the airways in asthma: observations and consequences. Clin Sci (Lond) 2005; 108: 463-477.

29 Helenius I, Lumme A, Ounap J, et al. No effect of montelukast on asthma-like symptoms in elite ice hockey players. Allergy 2004; 59: 39-44.

30 Sue-Chu M, Karjalainen EM, Laitinen A, Larsson L, Laitinen LA, Bjermer L. Placebo-controlled study of inhaled budesonide on indices of airway inflammation in bronchoalveolar lavage fluid and bronchial biopsies in cross-country skiers. Respiration 2000; 67: 417-425.

31 Koskela HO. Cold air-provoked respiratory symptoms: the mechanisms and management. Int J Circumpolar Health 2007; 66: 91-100. 